\title{
7th International Bielefeld Conference 2004
}

\author{
Held 3-5 February 2004, Bielefeld, Germany
}

\begin{abstract}
The 7th International Bielefeld Conference 2004 was organized under the title Thinking Beyond Digital Libraries Designing the Information Strategy for the Next Decade. This conference report is a condensed and revised review based on an article compiled by Regina Goldschmitt [1], librarian of the Max Planck Institute for Research on Collective Goods, Bonn, Germany.
\end{abstract}

\section{Introduction}

The Bielefeld University Library has hosted again the 7th International Bielefeld Conference "Thinking beyond Digital Libraries - Designing the Information Strategy for the Next Decade" [2].

The 7th Bielefeld Conference was the first conference under the new leadership of Dr. Norbert Lossau, Librarian of the Bielefeld University Library, and this conference has maintained its traditional technical focus of the earlier Colloquia, ${ }^{1}$ while placing more emphasis on research libraries.

Prominent speakers from Great Britain, the USA, Australia, Norway, the Netherlands and Germany highlighted their experiences both in academia and business, and they took part in lively discussions with the almost 500 delegates from over 30 countries.

\section{Conference themes}

Major themes of the conference included:

- the strategic positioning and future direction of research libraries and their parent institutions higher education with profiles built by concentrating on customers and new services;

- the electronic publication of research papers, access to and networked use of on-line resources;

- the dissemination of IT-skills.

The profile of an institution of higher education and its attractiveness to both students and academic staff depends heavily on the information services it is able to offer. Here, libraries can take on an active roll in creating excellence in universities. The future importance of a library will be measured by the benefits to its users. Technical services such as the acquisition and cataloguing are still relevant and have been automated, but major emphasis now is on user-related services, which include:

\footnotetext{
${ }^{1}$ The Conference was a continuation of the well-known Bielefeld Colloquia and have taken place every two years since 1992, with the aim of discussing innovative technologies, products and technical services for library, information and communication sciences. The 8th Bielefeld Conference will be held in 2006.
} 
- access to local, regional and global resources (online catalogues, electronic newspapers, descriptive and full-text databases, internet sources and digitized objects, etc.) via portals;

- the introduction of personal search profiles, intuitively led and connected search queries;

- direct links to the full-text from the search results;

- automated current awareness services;

- e-learning;

- the acquisition and evaluation of relevant internet resources;

- publication of digital dissertations, course materials, multimedia documents, preprints and research data on university-owned servers.

\section{Keynote speaker}

Prof. Donald A. Marchand (Professor of Strategy and Information Management at Lausanne and chairman of enterpriseIQ) explained how corporate and academic managers can improve the productivity of their companies by using and organizing information more effective and how they achieve a higher output from their information resources and technologies. Marchand stressed the need for:

- Information policy, including evaluation of information (e.g. integration, formality, monitoring, transparency, the sharing and transmission of information);

- Information management (the collection, organization, provision, preparation and further processing of information);

- Information techniques (various information technologies, which aim to support the management of the company, the development of innovative solutions, certain internal business processes or certain operations).

This allows that:

- information is easily available to all, even across departments and company hierarchies;

- everyone in the company feels responsible for managing information, i.e. collecting, organizing and transmitting information;

- information management and technologies are treated as an integral part of the organization, not as having a merely supporting role;

- managers are acutely conscious of gaps in their knowledge.

\section{Further speakers}

Prof. William Dutton (Director of the Oxford Internet Institute at the University of Oxford) spoke about the importance of repositioning information and communication technologies in higher education. Dutton presented five theories regarding the current situation:

1. The information paradox consists in the fact that while the amount of information available (in new media, books, multimedia documents and on servers) is continually increasing, people cannot and do not want to read more.

2. Libraries find themselves in a transitional phase, as they adapt to the needs of an innovative higher education sector. 
3. The implementation of the strategic vision is not solely the responsibility of libraries and computer centers. The institutions as a whole can and must implement it.

4. Every opposition must be overcome - for example, of library versus information service or computer center, of electric versus printed information, or of centralized versus decentralized systems.

5. A sound budget is needed to find some way out of the present budget crisis.

To escape this problematic situation a strategic vision has to lead to quality information and information pathways to excellence in science and teaching.

Dr. Alan Bundy (University Librarian and Director of the Bob Hawke Prime Ministerial Library at the University of South Australia) believes that the modern academic library is the driving force for change in the area of education. Bundy calls for a change in the entire system of higher education in order to meet the demands of users. Libraries cannot manage this alone, but they must nevertheless participate in this transition and have a role in curriculum development.

Ingar Lomheim (Library Director at the Norwegian University for Science and Technology) reported about the effects on academic libraries caused by the reform of the higher education scene. Emphasis has been placed on electronic resources and connecting the library services to the learning system. The expansion of portals and the library consortium is a requirement. At Norwegian universities, librarians and tutors are working closely together to improve the information skills of their students.

Prof. Dr. Reinhold Decker (Department of Economics and Business Administration at the University of Bielefeld) showed how methods from consumer and market research can be used, when new services are introduced in libraries or other central institutions.

Winston Tabb (Dean of University Libraries and Sheridan Director at Johns Hopkins University) recommended that libraries cooperate more with marketing experts and technicians. In collaborative work, for example, it is possible to cost-effectively digitalize all sorts of documents, to look after metadata, to optimize the resources offered and to open up new avenues for scientific publishing (e.g. Project MUSE [3]). Tabb's view is: Consider where you might best expand, and be open to new directions!

Ann Wolpert (Director of MIT Libraries and Chair of MIT Press) stated that MIT is also investing in Internet-based knowledge for research and teaching as an information strategy for the next decade. On the one hand, MIT has a vision of freely sharing all of its content; on the other hand, copyrights and licensing contracts stand in the way of the seamless accessibility of information. Public sources and shared knowledge serve to counterbalance the traditional model of the oligarchic political publishing house. The MIT libraries work closely together with MIT university press and with SPARC. ${ }^{2}$ Together with Hewlett Packard, MIT librarians have developed the digital archive, DSpace [4]. DSpace manages, indexes and archives the intellectual output of universities in digital formats, and it stores it for possible future use. DSpace can be used and further developed by all research facilities worldwide as open source software.

Dr. Roswitha Poll (Director of the Munster University Library) introduced the initial results of the "usage analysis of a supra-regional system for providing literature and information". The study, which was carried out by the university library in Munster and the research institute INFAS and was funded by the German Research Foundation, covers an evaluation of the German Special Collection Programme

\footnotetext{
${ }^{2}$ SPARC is an initiative of research libraries, which is competing with the traditional science publication process. http://www.arl.org/sparc.
} 
("Sondersammelgebiete") from the perspective of the users. The results show that users want to read less. They want direct access to information, and they want it now or not at all. The disciplines clearly have different information policies and different information needs. The most typical problems in searching for information are that the users do not regard the information that they find as current enough, and that it is not available locally. The process of obtaining information is often thought to be too slow, too expensive and too time-consuming. Users want:

- more electronic newspapers and more digitized, relevant sources;

- personalized services;

- automatic notification systems;

- improved, expanded search instruments, which automatically offer limited searches, e.g. by means of key words, thesauri, classifications, etc.;

- integrated searches for interdisciplinary matters;

- simple and quick access to document delivery services;

- more help and guidance in acquiring information competence.

The "2003 OCLC Environmental Scan" 3 has shown very similar experiences and results. OCLC made the results of its comprehensive study available to the worldwide information landscape.

A further area of emphasis at the conference was the new orientation of academic online publication processes. One of the most important developments of recent years is certainly the establishment of Open Archives (or institutional depositories) at higher education facilities, as institutional electronic depots. Preprints can be found there, as well as electronic versions of dissertations, research data, teaching materials, and increasingly also articles that have gone through peer review processes. The Open Archives are in such great demand that they can no longer be ignored by publishers and cooperation between Open Archives and publishers is recommended.

Theresa Velden (Executive Director at the Heinz Nixdorf Center for Information Management in the Max Planck Society) introduced the Max Planck Society's "e-doc server".

In the future, librarians will advocate that researchers publish on their own institutions' servers. In contrast to publishing houses, universities or libraries are not interested in holding the author's exclusive rights, so nothing would stand in the way of works being published by publishing houses after they were published on university servers. Many university servers, however, do not have sufficient quality control procedures - the traditional domain of the publishers. Nor do they have effective models for making the documents available on a long-term basis. Here, new common solutions and business models are needed.

OCLC and VASCODA show two different approaches to global collaboration aimed at making scientific and research information available.

OCLC [5] was founded 45 years ago as a member-organized, non-profit organization, which received no public funding and charged no user's fees. More than 45,000 libraries in 84 countries now belong to the OCLC Association. Its central project is the gigantic catalogue "WorldCat", which has more than 52 million entries; cataloguing and library loans are organized in the association. For 25 years, OCLC has supported its members with new information technologies. OCLC supports the Dublin Core Metadata Initiative, tools for the Open Archive Harvesting and works closely with Dspace.

Strategic partners of OCLC are OCLC PICA, the British Library, HEBIS, GBV and Die Deutsche Bibliothek (DDB), as well as the Dynix corporation [6]. OCLC and DYNIX have announced a coop-

\footnotetext{
${ }^{3}$ The "2003 OCLC Environmental Scan" can be downloaded free of charge as a pdf file. It contains the issue areas: Social, Economic, Technology, Research \& Learning, Library Landscapes. http://www.oclc.org/membership/escan/.
} 
eration to connect the local Dynix library system with union cataloguing and bibliographical system of OCLC.

The German project VASCODA [7] is organized entirely differently, compared to the approach of OCLC. Here, Internet-based services already in existence (subject-based virtual libraries, expert data banks, subject-specific search engines) are brought together in a new portal, which operates as a marketplace where the different providers can offer their products. A single point of access for all specialist and interdisciplinary queries should, with the help of diverse search and service functions, produce multiple hits. Supported by the German Federal Ministry of Education and Research (BMBF) and the German Research Foundation (DFG), the interdisciplinary search engine is in operation since August 2002. Partners are the German Union Catalogue of Serials (ZDB), Die Deutsche Bibiliothek (DDB), the Consortium of Library Networks (AG Verbundsysteme) and the Electronic Journals Library (EZB).

The Norwegian company FAST Search \& Transfer [8], developers of search engine technology, was a sponsor of the Bielefeld Conference. The company is also a partner of the University of Bielefeld's library in a joint project, which was introduced at a workshop of the conference.

FAST uses a technology that evaluates and classifies in advance the servers to be accessed. The servers send an automatic message if they have an interesting source at their disposal, allowing search queries involving billions of documents with extraordinary speed.

Marc Krellenstein (vice-president of Elsevier) believes that the search technologies presently available are good enough to cope with general or simple queries within a certain documentation collection. The real challenges are in the academic, professional areas:

1. Simplified access to the materials is necessary: increasingly large and separate data banks should be integrated, while precision in searching for or requesting data must be improved. Integration and precision can be achieved by employing an evaluative XML based search, which can be further supported by "meta searches".

2. Tools must be developed and made available both for more precise, complex searches (here diverse methods for evaluating relevance are employed) and for navigation aids that enable discoveries to be made intuitively.

The solution lies in document clustering: the results are combined in groups of topics, facts, names, times, sources, etc. These themed groups are produced either statically, from the fixed categories of the metadata, or dynamically, from the analysis of the results. With the help of clusters, the end-user can simplify a search, narrow it down, or make it clearer; he can hierarchically navigate through long lists of results, and he will be referred to new aspects, sources and contexts.

Dr. Christine Thomas (The German Federal Ministry of Education and Research) underlined the need for dynamic infrastructures in science. Scientific work of tomorrow will take place in dynamicallyformed international, interdisciplinary collaborative teams. The German GRID initiative for e-science aims:

- the establishment of a GRID infrastructure and of middleware;

- the support of pilot projects;

- assistance in developing standards and rules; and

- international networking.

The goal of the structure planned for the future is to provide a virtual knowledge environment of digital libraries in a dynamic infrastructure with innovative, net-based information services for scientific work and research in Germany. 


\section{References}

[1] See also BuB 4/2004, pp. 286-289 (in German), Library Hi Tech 4/2004 (in English). By Regina Goldsmith, e-mail: golds@mpp-rdg.mpg.de.

[2] http://conference.ub.uni-bielefeld.de/proceedings.

[3] Project MUSE offers more than 200 specialist research journals online in full text. Online access is available upon subscription. http://muse.jhu.edu.

[4] http://www.dspace.org.

[5] http://www.oclc.org.

[6] http://www.oclcpica.org/?id=1374\&ln=uk.

[7] http://www.vascoda.de.

[8] http://www.fastsearch.com. 